\title{
A CONSTITUCIONALIDADE DO POLIAMOR: POSSÍVEL APLICABILIDADE DO DIREITO SUCESSÓRIO AOS COMPANHEIROS DAS ENTIDADES POLIAFETIVAS
}

\author{
Camyla Galeão de Azevedo ${ }^{1}$ \\ Thiago Augusto Galeão de Azevedo
}

RESUMO: A legislação e a jurisprudência pátria não concedem reconhecimento às famílias poliamorosas sob o argumento de que no Brasil, a monogamia é um princípio basilar da sociedade. Entretanto concluímos pelo reconhecimento do poliamor como uma família legítima ao recebimento da tutela protetiva do Estado e dos direitos sucessórios. A teoria utilizada para a aplicação dos direitos sucessórios aos companheiros foi a teoria da triação, entendimento que vem sendo aplicado em alguns Tribunais de Justiça Brasileiros. Desta feita, através da aplicação desta teoria, a pesquisa conclui-se com a possibilidade de concessão dos direitos sucessórios aos companheiros da relação.

Palavras-chave: Poliamor; Direito sucessório; Monogamia; Afetividade; Dignidade da Pessoa Humana.

\section{THE CONSTITUTIONALITY OF THE POLYAMORY: POSSIBLE APPLICABILITY OF THE SUCCESSORY RIGHT TO THE COMPANIES OF THE POLIAFETIVE ENTITIES}

\begin{abstract}
The legislation and the jurisprudence homeland don't grant recognition to the families poliamorosas under the argument that in Brazil, the monogamy is a basic beginning of the society. However we ended for the recognition of the polyamory as a legitimate family to the reception of the protective protection of the State and of the rights sucessórios. The theory used for the application of the rights sucessórios to the companions was the theory of the triation, understanding that has been applied in some Brazilian Tribunals of Justice.
\end{abstract}

Keywords: polyamory; succession law; Monogamy; Affectivity; Human Dignity.

\footnotetext{
${ }_{1}$ Mestranda em Direito, Políticas Públicas e Desenvolvimento Regional - CESUPA. Advogada. Endereço eletrônico: camylagaleao.a@hotmail.com.

2 Doutorando em Direito - UNB. Mestre em Direito - CESUPA. Pós-graduado em Direito Civil - PUC MG. Professor do curso de Direito - CESUPA. Advogado. Endereço eletrônico: thiagogaleao@hotmail.com.
} 


\section{INTRODUÇÃO}

O Direito Civil vem sofrendo profundas transformações positivas no ordenamento jurídico brasileiro. Apesar do significativo avanço, o ordenamento jurídico brasileiro ainda não concedeu reconhecimento às famílias poliamorosas.

Cumpre asseverar que as famílias poliamorosas são formadas por uma relação afetiva íntima entre mais de duas pessoas, que de forma explícita, gozam de suas liberdades e autonomias de vontade, para se inter-relacionarem afetiva e sexualmente com seus parceiros.

Mesmo sem o reconhecimento na Constituição Federal ou no Código Civil, no ano de 2012 foi registrado, por meio de cartório de registro civil, a primeira união poliamorosa do país, envolvendo um homem e duas mulheres. Em outubro de 2015, o $15^{\circ}$ Ofício de Notas do Estado do Rio de Janeiro registrou a segunda União Estável envolvendo três pessoas no Brasil. Neste caso, a tabeliã Fernanda de Freitas Leitão, que formalizou a união, utilizou como fundamento jurídico o mesmo determinado em 2011 pelo Supremo Tribunal Federal após reconhecer legalmente os casais homossexuais, baseado na dignidade da pessoa humana e na tese de que o conceito de família é aberto e plural.

Além desses dois casos registrados, de acordo com o Jornal Folha de São Paulo (2016), até o final do ano de 2016, existiam pelo menos 8 registros de mesma natureza no país (FOLHA DE SÃO PAULO, 2016, online).

Apesar das famílias poliamorosas já estarem sendo reconhecidas em diversos cartórios de pessoas do país, o reconhecimento pelo ordenamento jurídico como um todo ainda não se concretizou. Consequentemente, não lhes são concedidos os devidos direitos decorrentes dessa relação familiar.

Por considerarmos uma família legítima ao recebimento da tutela jurídica, quanto aos efeitos sucessórios decorrentes da união, cumpre-nos analisar a possibilidade de concessão dos direitos sucessórios aos companheiros da relação poliamorosa, com base nos princípios da igualdade, afetividade e liberdade. Após analisarmos a possibilidade de aplicação dos direitos sucessórios aos companheiros do poliamor, analisaremos de que forma a partilha de bens será realizada. 


\section{A CONSTITUCIONALIDADE DO POLIAMOR: POSSÍVEL APLICABILIDADE DO DIREITO SUCESSÓRIO AOS COMPANHEIROS DAS ENTIDADES POLIAFETIVAS}

\section{\begin{tabular}{lllllll}
\hline 1 & ASPECTOS & FUNDAMENTAIS & PARA & A & CARACTERIZAÇÃO & E
\end{tabular} RECONHECIMENTO DO POLIAMOR COMO ENTIDADE FAMILIAR}

O art. 226 da Constituição Federal (BRASIL, CF/88) reconheceu as famílias de forma diversa do Código Civil de 1916. Infere-se, como já explicitado no capítulo anterior, a partir da leitura do dispositivo, que a família matrimonializada não é mais o único modelo de família reconhecido pelo Poder Constituinte. Além da união estável, a Constituição Federal entendeu as entidades monoparentais como família.

Insta consignar se o artigo 226 da Constituição Federal trata das famílias de forma taxativa, reconhecendo apenas essas famílias existentes, ou se trata de forma exemplificativa, de modo que possam ser reconhecidas outras entidades familiares que não estão constitucionalizadas, para fins de reconhecimento da entidade poliamorosa como entidade familiar.

Tem-se um embate hermenêutico que determina o uso da interpretação sistemática. As normas de direito de família e as que referem-se à ela são normas de inclusão. "A necessidade de valorização da família tem sido entendida como caminho a ser perseguido por todas as nações, como forma de criar uma sociedade sólida, solidária e justa a partir de sua célula mãe, que é a unidade familiar” (FERRARINI, 2010, p. 104). Para, justamente fazer jus à essa proteção nacional, a Constituição Federal determinou uma “especial proteção do Estado” para as famílias. (BRASIL. CF/88).

No que tange à especial proteção que a Constituição Federal confere às famílias, Gustavo Tepedino (1999, p.326-327), na obra Temas de Direito Civil, entende que a especial proteção conferida entrevê o seu importante objetivo na promoção da dignidade humana. As entidades familiares, entretanto, deverão internamente, promover a dignidade e a realização dos seus componentes, entendimento este diretamente ligado ao princípio da afetividade e ao novo modelo de família.

Em razão de possuírem especial proteção do Estado e por serem normas de inclusão, Flávio Tartuce (2017,p.39) aponta que o rol do art. 226 não é taxativo, mas meramente exemplificativo, de modo que enseja a interpretação extensiva e ampla das estruturas familiares da Constituição. Ressalta ainda que, qualquer projeto de lei será inconstitucional se o seu objetivo for restringir o conceito de família. 
A exclusão das outras entidades familiares por não estarem previstas no rol do art. 226 da Constituição Federal não decorre da interpretação literal do artigo, mas tão somente de uma interpretação restritiva e preconceituosa da Constituição. Os autores Cristiano Chaves de Farias e Nelson Rosenvald (2016, p. 75) entendem no mesmo sentido, pois essa forma de interpretação colidiria diretamente com o princípio da dignidade da pessoa humana e da igualdade substancial, por não ser possível qualquer descriminação à qualquer espécie familiar disponível à opção afetiva de cada cidadão. Em razão de não ter essa interpretação restritiva, asseveram ainda que, por isso, estão admitidas todas as entidades familiares formadas com base no afeto, na ética e na solidariedade recíproca.

Em razão da especial proteção, tem-se que a atuação do estado na intervenção estatal deve ocorrer apenas no sentido em que proporcione proteção à essas famílias e, nunca à exclusão delas. Em razão da natureza que é dada à norma, é que se considera o conceito de família plural.

A necessidade de se promover a especial proteção das famílias, além de ser questão puramente constitucional, é plenamente utilizada pelo Supremo Tribunal Federal, pelo Superior Tribunal de Justiça e pelos outros Tribunais a fim de justificar e reconhecer outras famílias que não foram previstas expressamente pelo art. 226. Um julgado que ilustra muito bem isso, foi o que reconheceu a possibilidade de conversão de união estável em casamento para casais do mesmo sexo em 2013. O Supremo Tribunal Federal entendeu que a conversão é devida, de modo que não há nenhuma vedação legal expressa e que é pelo casamento que o Estado protege melhor a família.

A Constituição Federal, ao não elencar de forma taxativa o rol de todas as entidades familiares tuteladas pelo Estado, e, por não haver previsão vedando sua existência, não possibilita entender as famílias poliamorosas como entidades familiares inconstitucionais. Além de não existir nenhum desses dois pontos mencionados em relação à essas entidades, a Constituição Federal ao tratar das famílias, tem por objetivo oferecer “especial proteção” a elas, de forma a incluir famílias e direitos ao seu poder de proteção.

\subsection{AS ENTIDADES POLIAFETIVAS}




\section{A CONSTITUCIONALIDADE DO POLIAMOR: POSSÍVEL APLICABILIDADE DO DIREITO SUCESSÓRIO AOS COMPANHEIROS DAS ENTIDADES POLIAFETIVAS}

A prática poliamorista é muito antiga, praticada desde os tempos da monarquia. Apenas em 1990, impulsionada pelos movimentos feministas, foi que se reconheceu o poliamor com identidade relacional.

Os movimentos feministas, segundo o autor Rafael da Silva Santiago (2014, p.111) em dissertação de mestrado publicado pela Universidade de Brasília, propagou diversas críticas ao casamento, fazendo alusão à submissão da mulher ao marido, proporcionando o surgimento de ideais que se fazem como base do poliamor, como o carinho, o afeto, a atenção entre os membros de uma mesma família.

O poliamor surgiu a partir de vários movimentos pautados na libertação sexual sob relacionamentos alternativos "com o objetivo de promover o espaço e o conjunto de valores éticos pertinentes a estilos de vida alternativos e a relacionamentos íntimos, sexuais e/ou amorosos que não observavam o senso comum da cultura da 'monogamia compulsória' (HARITAWORN; LIN; KLESSE, 2006, p. 518) (SILVA SANTIAGO, 2014, p. 111).

Classificando a nomenclatura “poliamor” Pilão e Gondenberg (2012) explicam que:

O termo Poliamor é uma combinação do grego [poli (vários ou muitos)] e do latim (amor). No site do Poliamor Brasil, ele é descrito como uma recusa da monogamia como princípio e necessidade, o que possibilita a vivencia de "muitos amores" simultâneos de forma profunda e duradoura (PILÃO; GOLDENBERG, 2012, p. 63).

As entidades poliafetivas consistem em apenas uma relação formada por mais de duas pessoas que se interelacionam entre si, mutuamente e conscientemente das relações que mantêm, sob o intuito duradouro e com a intenção de se constituir em família.

Para Deodato José Ramalho Neto (2015, p.178), em artigo publicado pelo CONPEDI e conceituando o poliamor de forma similar, todas as pessoas que se envolvem nessa relação gozam da autonomia da vontade, de modo que escolhem viver nessa família a fim de encontrarem realizações pessoais e encontrar a felicidade.

Como podemos auferir das conceituações supramencionadas, os membros do poliamor organizam-se desta forma exercendo a sua autonomia da vontade e autodeterminação de assim se relacionarem. Cada indivíduo tem sua maneira de exercer seus direitos, escolhas, atividades e afetos que lhe proporcionam prazer e felicidade de formas distintas. No poliamor não é diferente, pois possuem escolhas tão distintas a ponto de que, ao invés de se relacionar apenas com uma pessoa, preferem se relacionar com mais de uma como forma de alcance da realização 
pessoal e a felicidade plena de cada um dos integrantes. Em razão da liberdade de autodeterminação e escolha, o Estado não tem o poder de interferir nas preferências pessoais desses indivíduos.

O vínculo que nutre os integrantes do poliamor é o afeto nutrido entre seus entes, que amam mais de uma pessoa e, geralmente, não são nutridos por questões sociais, patrimoniais ou religiosas como rege a maioria dos casamentos monogâmicos atuais, mas organizam-se desta maneira em busca de sua plena realização pessoal, protegida pela dignidade da pessoa humana.

Entende Rafael Santiago (2014) que o afeto é o princípio norteador do Direito de Família e que se faz imprescindível para o reconhecimento jurídico do poliamor, já que esta entidade se relaciona pautada nesse sentimento.

Portanto, diante da divergência doutrinária quanto à sua natureza jurídica, faz-se mister demonstrar, com apoio na teoria dos princípios do professor gaúcho Humberto Ávila, que a afetividade é um princípio norteador do Direito de Família, providência imprescindível para o reconhecimento jurídico do poliamor, já que essa identidade relacional se funda no afeto (SANTIAGO, 2014, p.10).

Diferentemente de outras relações, como será tratado adiante, os membros da entidade poliafetiva são conscientes de cada um dos membros com que se relacionam, amam-se mutuamente e coexistem em razão da sua vontade. Por esse motivo, a maioria das entidades poliamorosas mantém o respeito e a fidelidade entre si, o que a diferencia de outras entidades ou até mesmo do concubinato.

Com relação aos requisitos que a maioria da doutrina usa para caracterizar uma entidade como entidade familiar, não é coerente considerar que as entidades poliamorosas não se enquadram nessa classificação.

A autora Liz Helena Silveira do Amaral Rodrigues (2013, p. 13), em artigo publicado pelo CONPEDI, entende da mesma forma, no sentido que a entidade poliamorosa cumpre com todos os requisitos, já que o poliamor se distingue da infidelidade, do adultério, da poligamia e da relação paralela (conforme será demonstrado no próximo tópico), em razão das entidades poliafetivas se pautarem na aceitação e conhecimento das relações que são envolvidas.

Primeiramente, o fundamento que une as pessoas em poliamor é o afeto. Este é a razão principal e de também principal questionamento da doutrina contrária ao reconhecimento. As pessoas estão ligadas exatamente pelo vínculo afetivo com seus companheiros, “necessários a 


\section{A CONSTITUCIONALIDADE DO POLIAMOR: POSSÍVEL APLICABILIDADE DO DIREITO SUCESSÓRIO AOS COMPANHEIROS DAS ENTIDADES POLIAFETIVAS}

satisfazer a vontade e necessidade do indivíduo” (RODRIGUES, 2013, p.13). O afeto se tornou ponto fundamental para fins de preenchimento da família, inclusive, para a maioria dos autores a família é considerada como grupo social fundado essencialmente nos laços de afetividade.

A afetividade deverá estar, entretanto, acompanhada necessariamente dos elementos da estabilidade e da ostentabilidade, pois estas concomitantemente, corroboram o princípio da afetividade presente nas relações. É como entende Ricardo Lucas Calderón (2013), em dissertação de mestrado aprovado junto à Universidade Federal do Paraná:

Há que se destacar, ainda, que tal conjunto fático indicativo da afetividade deverá estar corroborado pela presença dos elementos da estabilidade e da ostentabilidade, de modo que apenas a presença concomitante desses elementos poderá indicar a constatação dessa afetividade familiar gradora de efeitos jurídicos (o que permitirá afastar casos de manifestações afetivas eventuais ou fugazes, que não merecem tal configuração) (CALDERÓN, 2013, p. 12).

A segunda característica suscitada pela doutrina é a estabilidade. Esta também de fácil previsão nesta relação já que os membros mantém fidelidade entre si, pois apenas relacionamse com os membros da própria família. A estabilidade, como será tratado posteriormente, é a principal característica que as difere dos outros tipos de relacionamento.

Distintamente das outras entidades, ou mesmo relações, apesar de se relacionarem com mais de uma pessoa, os participantes conhecem da relação e dos parceiros envolvidos nela. O poliamor tem como princípio "que todas as pessoas envolvidas estão a par da situação e se sentem à vontade com ela” (LINS, 2010, p.44). Além de todos os companheiros estarem cientes das relações mantidas, apoiam-nas e participam delas. Segundo a autora Liz Helena (2010), ainda sobre o artigo publicado pelo CONPEDI: "Esta é, salvo melhor juízo, a característica que melhor distingue o poliamor de outras entidades a relação com outros companheiros e consensual e apoiada por todos os envolvidos” (RODRIGUES, 2013, p.13).

É possível também observar a convivência pública das famílias, já que muitas delas, inclusive formalizam as relações em cartório de pessoas e aparecem para a sociedade como uma única família. Pela alta pressão social e religiosa, muitas vivem escondidas com medo de represálias e discriminações da sociedade e do Estado. 


\subsection{O DIREITO SUCESSÓRIO NAS ENTIDADES POLIAFETIVAS}

No âmbito dos efeitos jurídicos, um dos efeitos de grande relevância da existência e reconhecimento das entidades poliafetivas é o direito sucessório. Por ser um tema tão novo, cogita-se como o direito sucessório será aplicado às entidades poliafetivas, se a estrutura do Código Civil de 2002 é em, quase totalidade, pautada na família monogâmica.

Além do Código Civil de 2002 em nada estar pautado para a tutela das famílias poliafetivas, a jurisprudência e, grande parte da doutrina, já não são nada favoráveis ao reconhecimento do poliamor, quanto mais à tutela dos efeitos jurídicos decorrente da existência e reconhecimento dessas entidades familiares.

Insta consignar que a maioria das jurisprudências dos Tribunais Superiores, quando deparam-se com dualidade de relacionamentos, como no caso do cônjuge manter suas relações simultâneas, posicionam-se no sentido de não conceder direitos sucessórios para a segunda família, tida como adulterina. É o que se depreende do julgado do Superior Tribunal de Justiça:

AGRAVO REGIMENTAL - AÇÃO DE RECONHECIMENTO DE CONCUBINATO POST MORTEM - DECISÃO MONOCRÁTICA PROVENDO O RECURSO ESPECIAL, PARA REJEITAR O PEDIDO. INSURGÊNCIA DO MINISTÉRIO PÚBLICO FEDERAL - CONCUBINATO SIMULTÂNEO A CASAMENTO VÁLIDO PEDIDO DE PARTILHAMENTO DE PENSÃO PREVIDENCIÁRIA PELA CONCUBINA IMPOSSIBILIDADE EM RAZÃO DE INEXISTÊNCIA DE SEPARAÇÃO DE FATO OU DISSOLUÇÃO DO VÍNCULO CONJUGAL - FATO IMPEDITIVO AO RECONHECIMENTO DA 'UNIÃO ESTÁVEL' OBSTANDO A CONCESSÃO DE DIREITOS HEREDITÁRIOS OU PREVIDENCIÁRIOS À DEMANDANTE - ENTENDIMENTO PACÍFICO ANTE A SEGUNDA SEÇÃO DESTA CORTE - RECURSO DESPROVIDO (BRASIL. STJ.2012) (grifo nosso).

Da interpretação do julgado supramencionado, é possível concluir que, por estar pautado na imposição da monogamia, os Tribunais Superiores não autorizam a aplicação de qualquer efeito sucessório às entidades simultâneas. Entretanto, como já mencionamos, esse tratamento é tido como um tratamento discriminatório, já que é dever do estado efetivar a proteção especial à todas famílias, incluindo-as na concessão de seus efeitos jurídicos. 


\section{A CONSTITUCIONALIDADE DO POLIAMOR: POSSÍVEL APLICABILIDADE DO DIREITO SUCESSÓRIO AOS COMPANHEIROS DAS ENTIDADES POLIAFETIVAS}

Em razão do ordenamento jurídico brasileiro negar direitos para os concubinos, quando o cônjuge não está separado de fato e em razão das famílias poliamorosas já estarem sendo reconhecidas no Brasil, questiona-se se e como o direito sucessório será aplicado aos companheiros da relação afetiva. Faz-se necessário questionar também se todos deverão ter os mesmos direitos na herança, mesmo aqueles que tiverem uma menor participação financeira na formação do patrimônio comum.

São questões problemáticas, pois não há qualquer embasamento e reconhecimento jurisprudencial sobre o tema.

Diante da importância do direito sucessório brasileiro, da inaplicação do direito sucessório às entidades simultâneas pelos Tribunais Superiores, a aplicação do direito sucessório às famílias poliamorosas se torna controversas, de modo que o direito sucessório foi institucionalizado, visando a aplicação apenas para as famílias tradicionais, composta por casais formados de dois integrantes. Dessa forma, frente ao reconhecimento e à problemática de aplicação do direito sucessório, que surge a seguinte questão: como o direito sucessório será aplicado aos companheiros das entidades poliafetivas?

\section{A APLICAÇÃO DO DIREITO SUCESSÓRIO AOS COMPANHEIROS INTEGRANTES DA ENTIDADE POLIAFETIVA}

Apesar do Código Civil e a doutrina clássica serem relativamente “retrógrados”, fincados em preceitos tradicionais a fim de padronizar um modelo ideal de sexualidade, podemos afirmar que a fonte do direito que mais tem contribuído para a evolução dos institutos familiares, como o direito sucessório às famílias concomitantes, é a jurisprudência (PREREIRA, 2012, p.51).

Apesar de a legislação silenciar sobre o tema, é possível fazer uma reinterpretação, estendendo-se os direitos concedidos aos integrantes das relações monogâmicas aos das relações poliamorosas.

O direito sucessório poderá ser aplicado às entidades poliamorosas a partir de uma análise que já vem sendo adotada por alguns Tribunais de Justiça Brasileiro: a teoria da triação de bens. Essa teoria, tem também por fundamento, a aplicação, valorização e resguardo do princípio da afetividade. 
O autor Rodrigo Pereira da Cunha (2012), ao tratar da evolução proporcionada pela jurisprudência no ordenamento jurídico, introduzindo novos termos, destacou a partilha de bens na forma de triação, conforme o julgado da Apelação Cível 70.039.284.542 de 2010, proveniente do Tribunal de Justiça do Rio Grande do sul, pela qual destacou o seguinte trecho da decisão:

Reconhecimento de união dúplice que impõe partilha de bens na forma de “triação”, em sede de liquidação de sentença, com a participação obrigatória da esposa formal. Precedentes jurisprudenciais.

Ex-companheira que está afastada há muitos anos do mercado de trabalho, e que tem evidente dependência econômica, inclusive com reconhecimento expresso disso no contrato particular de união estável firmado entre as partes. De rigor a fixação de alimentos em prol dela. Adequado o valor fixado a título de alimentos em prol do filho comum, porquanto não comprovada a alegada impossibilidade econômica do alimentante, que inclusive apresenta evidentes sinais exteriores de riqueza.

APELO DO RÉU DESPROVIDO. APELO DA AUTORA PROVIDO. EM MONOCRÁTICA. (PEREIRA, 2012, p.51).

O termo "triação" de bens foi consolidado em 2005, através de uma decisão do Desembargador Rui Portanova. No caso concreto, foi reconhecida a existência de duas uniões estáveis simultâneas e paralelas. Em razão da realidade fática que se perfazia na existência de dois relacionamentos, admitiu-se a partilha de bens entre o “de cujus” e suas duas companheiras simultâneas. É como nos explica Jones Figueiredo Alves, Presidente do IBDFAM:

A expressão "triação" foi cunhada em decisão do des. Rui Portanova (2005),

quando demonstrada a existência de outra união estável em período concomitante a uma primeira união estável. Admitiu-se, então, que os bens adquiridos na constância das uniões dúplices fossem partilhados entre as companheiras e o “de cujus”. (TJRS, 8 $8^{\text {a }}$ Câmara Cível, Apelação Cível no 70011258605, j. Em 25/08/2005). Naquele mesmo ano, o tribunal gaúcho já houvera reconhecido efeitos jurídicos às uniões paralelas (ALVES, 2014, online).

A teoria da triação de bens, foi reconhecida por alguns Tribunais Brasileiros ao reconhecer a existência de dois relacionamentos simultaneamente por uma mesma pessoa. Ao reconhecer dois relacionamentos, ao invés de tutelar os direitos para apenas uma das conviventes, protege-se ambas, já que não haveria como negar ou excluir esses direitos de uma 


\title{
A CONSTITUCIONALIDADE DO POLIAMOR: POSSÍVEL APLICABILIDADE DO DIREITO SUCESSÓRIO AOS COMPANHEIROS DAS ENTIDADES POLIAFETIVAS
}

relação evidentemente simultânea, na qual o indivíduo amava e se relacionava com duas pessoas ao mesmo tempo. Além disso, tutelar apenas uma dessas famílias, quando ambas eram mantidas ao mesmo tempo, viola sobremaneira a isonomia de tratamento das famílias, de modo que as situações são substancialmente iguais. Da mesma forma entende o relator José Fernandes de Lemos, no julgamento da apelação cível 296.862-5:

\begin{abstract}
Aliás, adotando-se a posição contrária, ou seja, a de que a duplicidade de relacionamentos afetivos acarreta a perda da affectio familiae e a quebra do dever de lealdade, seria forçoso concluir que tal perda e tal quebra não se restringiriam a uma das relações apenas, mas se estenderiam a todas. No caso

dos autos, considerando ilegítima a união afetiva da autora apelante, teríamos de admitir, por identidade de fundamentos, descaracterizada também a relação do réu apelado com sua outra companheira, ao menos durante o período em que verificada a simultaneidade, o que nos conduziria ao absurdo de, diante de duas famílias consolidadas no plano dos fatos, não conferir o devido reconhecimento jurídico a nenhuma delas. Por outro lado, tutelar apenas um dos relacionamentos, em desprezo do outro, implicaria clara ofensa à isonomia, por conferir tratamento distinto a situações substancialmente idênticas (BRASIL. TJPE. 2013) (grifos nossos).
\end{abstract}

É o que preleciona o julgado do Tribunal de Justiça de Pernambuco:

DIREITO DE FAMÍLIA. UNIÕES ESTÁVEIS SIMULTÂNEAS. RECONHECIMENTO. PARTILHA DE BENS. TRIAÇÃO.

1. Estando demonstrada, no plano dos fatos, a coexistência de duas relações afetivas públicas, duradouras e contínuas, mantidas com a finalidade de constituir família, é devido o seu reconhecimento jurídico à conta de uniões estáveis, sob pena de negar a ambas a proteção do direito.

2. Ausentes os impedimentos previstos no art. 1.521 do Código Civil, a caracterização da união estável paralela como concubinato somente decorreria da aplicação analógica do art. 1.727 da mesma lei, o que implicaria ofensa ao postulado hermenêutico que veda o emprego da analogia para a restrição de direitos.

3. Os princípios do moderno direito de família, alicerçados na Constituição de 1988, consagram uma noção ampliativa e inclusiva da entidade familiar, que se caracteriza, diante do arcabouço normativo constitucional, como o lócus institucional para a concretização de direitos fundamentais. Entendimento do STF na análise das uniões homoafetivas (ADI 4277/DF e ADPF 132/RJ). 
4. Numa democracia pluralista, o sistema jurídico-positivo deve acolher as multifárias manifestações familiares cultivadas no meio social, abstendo-se de, pela defesa de um conceito restritivo de família, pretender controlar a conduta dos indivíduos no campo afetivo.

5. Os bens adquiridos na constância da união dúplice são partilhados entre as companheiras e o companheiro. Meação que se transmuda em "triação", pela simultaneidade das relações.

6. Precedentes do TJDF e do TJRS (BRASIL. TJ/PE. 2013). (grifo nosso)

O Tribunal de Justiça de Pernambuco, ao estar demonstrado duas relações afetivas duradouras, estáveis, contínuas e com a finalidade de se constituir em família, reconheceu-lhes juridicidade sob pena de estar negando direitos às conviventes. Foi também utilizado como argumento a necessidade de proteção do Estado a essas famílias, de modo que este não atue com uma posição restritiva, com apenas um único conceito de família, já que o art. 226 da Constituição Federal, conforme fora tratado no segundo capítulo deste trabalho, não tem o rol taxativo de existência de família.

APELAÇÃO. UNIÃO DÚPLICE. UNIÃO ESTÁVEL. PROVA. MEAÇÃO." TRIAÇÃO ". SUCESSÃO. PROVA DO PERÍODO DE UNIÃO E UNIẪO DÚPLICE A prova dos autos é robusta e firme a demonstrar a existência de união entre a autora e o de cujus em período concomitante a outra união estável também vivida pelo de cujus. Reconhecimento de união dúplice. Precedentes jurisprudenciais. MEAÇÃO (TRIAÇÃO) Os bens adquiridos na constância da união dúplice são partilhados entre as companheiras e o de cujus. Meação que se transmuda em triação, pela duplicidade de uniões. DERAM PROVIMENTO À APELAÇÃO. POR MAIORIA. (SEGREDO DE JUSTIÇA) (BRASIL, TJRS. 2005).

UNIÃO ESTÁVEL. RECONHECIMENTO. DUPLICIDADE DE CÉLULAS FAMILIARES. O Judiciário não pode se esquivar de tutelar as relações baseadas no afeto, inobstante as formalidades muitas vezes impingidas pela sociedade para que uma união seja" digna "de reconhecimento judicial. Dessa forma, havendo duplicidade de uniões estáveis, cabível a partição do patrimônio amealhado na concomitância das duas relações. Negado provimento ao apelo (SEGREDO DE JUSTIÇA) (BRASIL, TJRS. 2005). 
Justo se faz, por uma análise das jurisprudências mencionadas e pela própria analogia com o direito sucessório aplicado às famílias monogâmicas, que a partilha de bens na forma de triação se aplique às famílias poliamorosas.

Pela triação de bens, ocorreria a repartição de bens em três partes (quando o caso se referir à uma relação à três): um terço da herança iria para uma das companheiras, a outra para a outra companheira, e a terceira parte para os filhos provenientes da relação familiar, quando houver. Essa divisão faz jus ao próprio artigo 1.832 do Código Civil em que o cônjuge da relação, quando concorrer com os filhos de casal, recebe quinhão igual aos dos filhos.

O artigo 1.832 do Código Civil determina que a herança deverá ser partilhada por cabeça entre os descendentes e o cônjuge, devendo a este, obrigatoriamente, ser reservada a quarta parte da herança, se referido cônjuge for ascendente dos herdeiros com quem concorrer.

Com efeito, se o casal possui dois filhos comuns, ao cônjuge caberá o mesmo valor conferido aos seus descendentes, porquanto a herança será dividida igualmente entre os três herdeiros. Entretanto, na hipótese da existência de mais de três filhos, o cálculo não será o mesmo, pois reservada estará a quarta parte da herança ao cônjuge (MENIN,2014, p. 9) (grifos nossos).

Em se tratando do percentual de vinte e cinco por cento que é assegurado aos cônjuges da relação, tem-se que no poliamor, dependendo do número de companheiros integrantes da relação, assegura-se ou não o percentual de $25 \%$ devido às relações monogâmicas. É evidente que, se houver 4 companheiras, a cota mínima de cada uma somará a totalidade da herança, o que se torna indevido, já que a cota-parte dos filhos da família deverá ser assegurada. Além da incerteza se a porcentagem será ou não aplicada, em razão de ser uma relação aberta entre seus integrantes, na qual todos estão fincadas por laços de afeto simultaneamente, não se saberia em tese, qual a filiação biológica dos filhos, já que todos se relacionam simultaneamente.

Desta feita, quando for possível, o percentual de 25\% será aplicado independentemente da origem da filiação, o que vai em contraposição com o posicionamento que é atribuído no caso de filiação híbrida do casal monogâmico, como entende a autora Márcia Maria Menin: "Pela interpretação do dispositivo legal em apreço, apenas se considera a divisão por cabeça e a reserva da quarta parte da herança se o cônjuge sobrevivente e o de cujus possuírem filhos comuns” (MENIN, 2014, p.9). 
Concorrendo com os ascendente da herança, deverá haver a partilha de bens por igual, pois é o que ocorre atualmente nas famílias monogâmicas, já que se ambos os ascendentes do morto estiverem vivos, competirá 1/3 da herança para cada parte. Concorrendo apenas com um ascendente todos deverão receber por igualdade de cotas.

Finalmente, não havendo descendentes, caso concorra com ascendente em primeiro grau, ao cônjuge tocará um terço da herança; caber-lhe-á a metade desta se houver um só ascendente, ou se maior for aquele grau, a teor do já mencionado art. 1.837 do vigente Código Civil. (GAGLIANO; PAMPLONA FILHO, 2016, p.169).

Na falta de todos os ascendentes e ausência de descendentes do de cujus, todas as companheiras deverão receber, em igualdade de condições, a totalidade da herança deixada pelo de cujus. É como assevera Pablo Stolze: "Por fim, na forma do art. 1.838, em falta de descendentes e ascendentes, será deferida a sucessão por inteiro ao cônjuge sobrevivente” (GAGLIANO, PAMPLONA FILHO, 2016, p.169).

Em consonância de entendimento, tratando sobre a triação de bens, Giovana Melo (2010) em artigo publicado pela PUC do Rio Grande do Sul, asseverou que o critério utilizado pela teoria da triação é um critério lógico e igualizador, pois se estamos diante de uma relacionamento paralelo, não mais podemos manter a divisão clássica do patrimônio, já que a relação é formada por mais de duas pessoas (MELO, 2010, p. 18).

Apesar do nome triação sugerir a repartição em três partes, nada impede que a divisão do patrimônio ocorra em quatro partes ou cinco, sendo proporcional ao número de companheiras que integrem a relação poliamorosa.

Apesar de alguns tribunais já sedimentarem a aplicação da triação de bens, o Superior Tribunal de Justiça já se manifestou pela inconstitucionalidade deste entendimento:

RECURSO ESPECIAL. DIREITO DE FAMÍLIA. UNIÕES ESTÁVEIS PARALELAS. IMPOSSIBILIDADE. VIOLAÇÃO DO PRINCÍPIO DA MONOGAMIA. PRECEDENTES ESPECÍFICOS DESTA CORTE. RECURSO ESPECIAL PARCIALMENTE CONHECIDO E, NESSA EXTENSÃO, PROVIDO (BRASI, STJ.2011)

O Recurso Especial supramencionado, recaiu sobre a decisão também já mencionada, do Tribunal de Justiça do Rio Grande do Sul que ao reconhecer a existência de duas relações 


\section{A CONSTITUCIONALIDADE DO POLIAMOR: POSSÍVEL APLICABILIDADE DO DIREITO SUCESSÓRIO AOS COMPANHEIROS DAS ENTIDADES POLIAFETIVAS}

simultâneas, concedeu-lhes como efeito jurídico decorrente da relação, a partilha de bens por meio da triação. O Superior Tribunal de Justiça reformou a mencionada decisão sob o argumento de que estaria violando o princípio da monogamia.

Cumpre-nos salientar, com respeito, que a decisão concedida por este Superior Tribunal configura-se em uma decisão incoerente e retrógrada. Ressalta-se que a monogamia não se coaduna em um princípio do direito, mas tão somente uma imposição religiosa e social da sociedade, impondo-nos uma falsa percepção de que as relações ideais são formadas única e exclusivamente por duas pessoas. Além disso, não há qualquer fundamento para que a monogamia se configure como um princípio do ordenamento jurídico brasileiro, já que o Estado é laico.

Cumpre-nos ressaltar também, que apesar da grande valorização concedida à monogamia, configurando-a como um princípio, esta sequer é mencionada pela Constituição como tal, ou se quer esta subtendida de forma implícita. É como também entende, o autor José Ramalho Neto (2015):

Para a abordagem do assunto, devem-se analisar quais os princípios e regras presentes no ordenamento jurídico brasileiro que tornam o tema controverso na doutrina. Afasta-se, de início, qualquer entendimento que considera a monogamia como princípio fundamental da Constituição Federal, pois não há qualquer disposição expressa ou mesmo implícita nesse sentido (NETO, 2015, p. 182).

Ao contrário, a afetividade sim se configura em um princípio de direito, que deve ser respeitado. O núcleo fundamentador que une os indivíduos em família e os torna integrantes de uma é unicamente o afeto. O Estado, como um garantidor de direitos e responsável à conferir especial proteção às famílias, tem como dever tutela-las de forma à inclui-las na sociedade e conceder-lhes seus direitos.

Desta forma, frente à incoerência da decisão do Superior Tribunal de Justiça em reconhecer as entidades, tem-se que a aplicação dos direitos sucessórios aos companheiros da relação poliamorosa deverão ser aplicados com base na teoria da triação de bens e, analogicamente aplicando-lhes as normas de sucessão dos cônjuges das relações monogâmicas, com fundamento no princípio da afetividade e dignidade da pessoa humana. 


\subsection{EQUIPARAÇÃO ENTRE OS COMPANHEIROS NO RECEBIMENTO DO QUINHÃO}

Ao reconhecer a validade do poliamor, é necessário que o ordenamento jurídico conceda tratamento igualitário entre todos os integrantes da relação, de modo que todos sejam considerados companheiros com relação ao de cujus.

A necessidade desse reconhecimento se dará em razão de atualmente o ordenamento jurídico brasileiro apenas reconhecer tratamento de companheiro(a) em uma relação, enquanto que todas as outras que sobrevierem, são concubinas indignas de receber proteção sucessória se o companheiro não estiver separado de fato.

Assevera o julgado do Tribunal de Justiça do Distrito Federal:

DIREITO CIVIL E CONSTITUCIONAL. RECONHECIMENTO DE UNIÃO ESTÁVEL. IMPOSSIBILIDADE DE CARACTERIZAÇÃO ANTE A EXISTÊNCIA DE MATRIMÔNIO DO DE CUJUS. OCORRÊNCIA DE POLIGAMIA DE FATO. AUSÊNCIA DE SEPARAÇÃO DE FATO E DE DIREITO. PRECEDENTES DO STF, STJ E

1. O legislador cuidou de resguardar os direitos dos que convivem maritalmente fora do casamento, já que a Constituição Federal, considerou a união estável entidade familiar (art. 226, § $3^{\circ}$ ). 2. Porém, visando conceder proteção preferencial ao casamento, o legislador vedou a configuração da união estável caso um dos conviventes fosse casado, com a exceção se separado de fato ou judicialmente. (artigo 1.723, $\S 1^{\circ}$ do Código Civil/2002). 3. A prova carreada aos autos revela que o de cujus manteve dois relacionamentos em concomitância com o casamento, extraconjugais e sucessivos, uma poligamia de fato, sem contudo, separar-se de fato de sua esposa, a apelante/ré. 4. Desta forma, não deve ser reconhecido como união estável o relacionamento estabelecido entre a apelada/autora e o falecido porquanto equivale a admitir como lícita e geradora de efeitos a figura da poligamia de fato. Seria o mesmo que premiar com direitos patrimoniais a quem praticou a conduta indesejável e vedada por lei, deixando a viúva legal, ora apelante/ré, cerceada dos seus direitos legalmente constituídos. Precedentes jurisprudenciais.

5. Recurso conhecido e provido (BRASIL. TJDF.2014) (grifo nosso) 
Conforme análise do julgado supramencionado, o tratamento que é conferido no caso de famílias poligâmicas é considerar apenas uma relação como relação conjugal e oficial e todas as outras como concubinas, as quais não terão quaisquer direitos.

Esse posicionamento, novamente, viola o princípio da igualdade, dignidade e afetividade.

Primeiramente, todos os companheiros são sujeitos de direitos e envolver-se em uma relação poliamorosa ou poligâmica não as torna indigna destes. Além disso, essas famílias são formadas por vínculos afetivos nutrido entre seus integrantes. Os companheiros, ao reunirem-se entre si, nutrem o sentimento de afeto e de amor. Em razão deste fato, todos estão envolvidos de igual maneira, sem qualquer distinções pessoais entre si.

Em razão de se envolveram pelo afeto, o ordenamento jurídico não deverá proporcionar tratamento distinto entre os companheiros da relação, pois presume-se que por estarem reunidos em uma mesma família, todos os indivíduos nutrem o mesmo afeto entre si. Em razão dessa situação, não é legítimo a realização de distinções na distribuição das respectivas cota-partes dos herdeiros.

Tratando da afetividade, Paulo Lôbo (2011) nos ensina que o princípio da afetividade acarretou grandes evoluções na família brasileira, de modo que especializa no âmbito familiar os princípios da dignidade da pessoa humana, da solidariedade e promovendo a convivência familiar e igualdade entre os cônjuges, companheiros e filhos integrantes da relação familiar:

[...] recebeu grande impulso dos valores consagrados na Constituição de 1988 e resultou da evolução da família brasileira [...]. O princípio da afetividade especializa, no âmbito familiar, os princípios constitucionais fundamentais da dignidade da pessoa humana (art. $1^{\circ}$, III) e da solidariedade (art. $3^{\circ}$, I), e entrelaça-se com os princípios da convivência familiar e da igualdade entre cônjuges, companheiros e filhos, que ressaltam a natureza cultural e não exclusivamente biológica da família (LOBO, 2011, p. 70).

Como fora mencionado no tópico anterior, todos os companheiros, independentemente de maior ou menor afetividade, tempo na relação ou qualquer fator de privilégio, receberão a mesma cota-parte em respeito ao princípio da igualdade e afetividade.

Desta feita, exemplificando um caso concreto, pouco importa se Joana vive na relação há mais de 10 anos e Maria 2 meses. Ambas receberão a mesma cota-parte, pois presume-se que ambas tem a mesma importância para o de cujus. 
Assim, presumindo a afetividade no núcleo familiar e levando em consideração o princípio da igualdade entre os companheiros, todos deverão receber suas cotas-partes em igualdade de condições, sem aplicação de privilégios, sejam eles de afetividade ou temporais, em analogia com o direito sucessório conferido aos cônjuges da relação monogâmica e com a aplicação fundamentada na teoria da triação de bens.

\section{CONSIDERAÇÕES FINAIS}

O ordenamento jurídico brasileiro no âmbito do direito civil, sofreu profundas transformações. Com a promulgação da Constituição Federal, houve uma significativa transição paradigmática na qual o indivíduo passou a ser o centro da tutela jurídica. Com a repersonalização do direito, colocando o indivíduo como prioridade no ordenamento, fazendo com que o Código Civil se despatrimonializasse, a Constituição Federal passou a reconhecer famílias que não são tradicionalmente aceitas pela sociedade. Houve o reconhecimento das famílias monoparentais e mais recentemente, o reconhecimento das famílias homoafetivas. Conforme fora exposto, o reconhecimento dessas famílias não tradicionais, tem como principal pressuposto o princípio da afetividade e a especial proteção às famílias que deverá ser concedida pelo Estado. Como reflexo dessa inovação jurídica, foi promulgado o art. 226 na Constituição Federal, pela qual o Estado deverá conferir especial proteção às famílias.

Foi analisado que o art. 226 da Constituição Federal não trata das famílias de forma taxativa. É dever do Estado conferir especial proteção a todas elas, de forma que agregue-as e não as exclua do âmbito protetivo estatal e jurídico. Em razão da não taxatividade, da especial proteção que o Estado deve conferir às famílias, da ausência de normas que disponham em contrário, constitucionalmente, defendemos pela constitucionalidade das relações familiares fundadas no poliamor. Além desses pressupostos, o poliamor se constitui em uma família legítima a receber tutela jurídica, já que preenche todos os requisitos para a configuração em uma entidade familiar, tais como: afeto, ostentabilidade e fidelidade.

Os membros do poliamor efetivamente nutrem dentre si sentimentos afetivos, amorosos que os fazem querer se unir com mais de uma pessoa. Frise-se que esse sentimento é nutrido por todos os integrantes, simultaneamente, e não por apenas um dos integrantes como ocorre na poligamia. 


\section{A CONSTITUCIONALIDADE DO POLIAMOR: POSSÍVEL APLICABILIDADE DO DIREITO SUCESSÓRIO AOS COMPANHEIROS DAS ENTIDADES POLIAFETIVAS}

Além de preencher os pressupostos que fazem as famílias poliamorosas se configurarem em uma entidade familiar, defendemos também a tese de que a monogamia não se configura em uma princípio do direito, como sustentam algumas doutrinas e a jurisprudência sedimentada pelo Superior Tribunal de Justiça, mas sim de uma mera imposição social.

Em virtude de todos esses fatores, analisados conjuntamente, entendemos pela constitucionalidade e legitimidade de reconhecimento das famílias poliafetivas. Apesar desse posicionamento ser contrário ao que entende os Tribunais Superiores, há alguns anos as famílias poliamorosas vêm sendo reconhecidas em cartórios judiciais por meio de união estável.

Frente a esses reconhecimentos, as formações familiares do poliamor, como qualquer outra, geram os efeitos jurídicos de cunho previdenciário, familiar e sucessório. Em razão da produção desses efeitos jurídicos decorrentes desses reconhecimentos, fez-se necessário a análise da problemática de um desses efeitos jurídicos provenientes desses reconhecimentos: os efeitos sucessórios, objeto deste estudo.

O Direito Sucessório Brasileiro, conforme analisado, tem como base as famílias monogâmicas, pois em se tratando da partilha de bens ou em qualquer outro dispositivo referente à sucessão, tratam do cônjuge de forma singular. Entretanto, apesar do Código Civil silenciar à respeito da possibilidade ou não da concessão desses direitos aos companheiros da relação poliamorosa, a jurisprudência majoritária segue no sentido de negar esses direitos aos membros da entidade familiar.

Entendemos pela incoerência da não concessão de direitos sucessórios aos membros das relações simultâneas como um todo. Isso decorre em razão do próprio princípio da dignidade e igualdade. Pois todos os indivíduos são sujeitos de direito e, se assim são, o simples fato de se unirem em uma relação familiar, não os torna indignos de recebimento da tutela jurídica. Segue-se no mesmo sentido pelo princípio da igualdade, pois nas famílias tradicionais e não tradicionais como as homoafetivas, são concedidos os direitos sucessórios. As famílias homoafetivas, assim como as entidades poliamorosas não são famílias tradicionais, mas são legítimas de recebimento de tutela jurídica. Assim, não se faz justo que uma dessas famílias seja legítima do recebimento de direitos sucessórios e a outra não.

Desta feita, frente à necessidade de reconhecimento da tutela sucessória aos membros do poliamor, foi analisado a forma em que se concretizará a partilha de bens aos companheiros da relação. Com base na igualdade de direitos, dignidade da pessoa humana e afetividade, esses 
direitos devem ser concedidos com fundamentos em princípios do direito, na teoria da triação de bens e analogia com o direito civil brasileiro.

Ao invés de apenas um dos cônjuges receber, que é como ocorre nos moldes do atual entendimento jurídico, por todos fazerem parte simultaneamente de uma mesma relação, todos deverão receber sua quota-parte em igualdade entre si.

Para que esse entendimento seja recebido pelo ordenamento jurídico brasileiro, defendemos a tese de que ao invés de propor um projeto de lei ou uma própria emenda constitucional, deverá ser realizado uma reinterpretação do próprio art. 226 da Constituição Federal, introduzindo no âmbito familiar as famílias poliafetivas, por meio da Mutação Constitucional, assim como dos demais dispositivos do Código Civil, pois ao invés de conferir direitos sucessórios à apenas um companheiro, deve-se conferir à todos os envolvidos de forma igualitária, justa e social.

\section{REFERÊNCIAS}

ALVES, Jones Figueiredo. Triação de Bens. Disponível em: < http://flaviotartuce.jusbrasil.com.br/artigos/121822664/triacao-de-bens-artigo-de-jonesfigueiredo-alves $>$. Acesso em: 24 de março de 2017.

ANDRADE, André Gustavo Corrêa de. O Princípio Fundamental Da Dignidade Humana E http://www.tjrj.jus.br/c/document_library/get_file?uuid=5005d7e7-eb21-4fbb-bc4d12affde2dbbe> . Acesso em 2 de abril de 2017.

AQUINO, Nara Pedrosa . O poliamor. Trabalho de Conclusão de Curso (Bacharelado em Direito) - Centro Universitário do Estado do Pará, 2015.

ASSESSORIA DE COMUNICAÇÃO DO IBDFAM. Escritura Reconhece União Afetiva a Três. 2012. Disponível em: < http://www.ibdfam.org.br/noticias/4862/novosite>. Acesso em: 18 de janeiro de 2017.

BAHIA, Cláudio José Amaral; LEÃO JUNIOR, Teófilo Marcelo de Arêa. O Afeto e a Afetividade Nas Relações Filiares Nas Novas Famílias. Artigo publicado pelo CONPEDI. 2010. em: http://www.publicadireito.com.br/conpedi/manaus/arquivos/anais/fortaleza/3519.pdf>. Acesso em: 05 de março de 2017.

BRASIL. Superior Tribunal de Justiça. Recurso Especial nº 1183378. Quarta turma cível. Brasília, Distrito Federal. 2011. Disponível em: < https://stj.jusbrasil.com.br/jurisprudencia/21285514/recurso-especial-resp-1183378-rs-20100036663-8-stj>. Acesso em: 08 de dezembro de 2017. 


\section{A CONSTITUCIONALIDADE DO POLIAMOR: POSSÍVEL APLICABILIDADE DO DIREITO SUCESSÓRIO AOS COMPANHEIROS DAS ENTIDADES POLIAFETIVAS}

. Tribunal de Justiça do Rio de Janeiro. Apelação n ${ }^{\circ} 00082087420108190209$. Oitava Câmara Cível. Rio de Janeiro. 2013. Disponível em: < https://tjrj.jusbrasil.com.br/jurisprudencia/117021165/apelacao-apl-82087420108190209-rj-0008208$7420108190209>$. Acesso em: 18 de maio de 2017.

. Tribunal de Justiça do Rio Grande do Sul. Apelação cível nº 70038296141. Sétima Câmara Cível. 2011. Disponível em: https://tjrs.jusbrasil.com.br/jurisprudencia/19958288/apelacao-civel-ac-70038296141-rs?ref=juris-tabs Acesso em: 05 de maio de 2017.

. Tribunal de Justiça do Distrito Federal. Apelação cível n 20130510057710 . Quinta turma cível. Distrito Federal. 2014. Disponível em: < https://tjdf.jusbrasil.com.br/jurisprudencia/135611408/apelacao-civel-apc-20130510057710-df0005681-1320138070005> . Acesso em: 06 de fevereiro de 2017.

Superior Tribunal de Justiça. Resp $\mathrm{n}^{0}$ 892300. 2011.Disponível em: https://stj.jusbrasil.com.br/jurisprudencia/18793398/peticao-de-recurso-especial-resp-892300. Acesso em: 05 de março de 2017.

. Tribunal Regional da $4^{a}$ Região. Embargos Infringentes $n^{0} 77956$. Terceira seção. 2010. Disponível em: < https://trf-4.jusbrasil.com.br/jurisprudencia/17487077/embargosinfringentes-einf-77956-pr-20037000077956-0-trf4>. Acesso em: 20 de janeiro de 2017.

Tribunal de Justiça de Santa Catarina. Embargos Infringentes $n^{0} 72985$. Grupo de Câmaras de Direito Civil. 2010. Disponível em: https://tjsc.jusbrasil.com.br/jurisprudencia/18476966/embargos-infringentes-ei-72985-sc-20100072985. Acesso em: 17 de janeiro de 2017.

. Superior Tribunal de Justiça. Agravo regimental no recurso especial $n^{\circ} 968572$. Quarta turma. 2012. Disponível em: https://stj.jusbrasil.com.br/jurisprudencia/21266417/agravo-regimental-no-recurso-especialagrg-no-resp-968572-rn-2007-0145060-0-stj?ref=juris-tabs. Acesso em: 08 de janeiro de 2017.

Supremo Tribunal Federal. Repercussão geral no recurso extraordinário no 878.694. 2015. Disponível em: < file://C:/Users/Camila-Pc/Downloads/texto_306841295\%20(1).pdf>. Acesso em: 15 de maio de 2017.

Tribunal de Justiça do Estado de São Paulo. Agravo de Instrumento $\mathrm{n}^{\circ}$ 20724617720168260000. Oitava câmara de direito privado. 2016. Disponível em:< https://tjsp.jusbrasil.com.br/jurisprudencia/361722775/agravo-de-instrumento-ai-

20724617720168260000-sp-2072461-7720168260000>. Acesso em: 05 de março de 2017.

Superior Tribunal de Justiça. AI no RESP no 1135354. Quarta turma. 2011. Disponível em: >https://stj.jusbrasil.com.br/jurisprudencia/21120937/arguicao-deinconstitucionalidade-no-recurso-especial-ai-no-resp-1135354-pb-2009-0160051-5-stj<. Acesso em: 08 de maio de 2017. 
CAHALI, Francisco Jose; HIRONAKA, Giselda Maria Fernades Novaes. Direito das Sucessões. $5^{\mathrm{a}}$ ed. São Paulo: Revista dos Tribunais.2014

CALDERÓN, Ricardo Lucas. Princípio da afetividade no direito de família. Rio de Janeiro: Renovar, 2013. Disponível em: < http://www.egov.ufsc.br/portal/sites/default/files/principio_da_afetividade_no_direito_de_fa milia.pdf $>$. Acesso em: 25 de fevereiro de 2017.

COSTA, Lívia Ronconi; SIMÕES, Thiago Felipe Vargas. A Família e a Constituição Federal De 1988. 2011. 20 Dispnível http://www.ibdfam.org.br/_img/artigos/A\%20Fam\%C3\%ADlia\%2005_10_2011.pdf. Acesso em: 14 de abril de 2017.

DIAS, Maria Berenice. Manual de direito das famílias : de acordo com o novo CPC. 11. ed. São Paulo: Revista dos Tribunais, 2016.

FARIAS, Cristiano Chaves de; ROSENVALD, Nelson. Curso de Direito Civil. Vol 6. $8^{\circ}$ Ed.Salvador- Bahia: Juspodivm. 2016.

FERRARINI, Letícia. Famílias Simultâneas e seus Efeitos Jurídicos: Pedaços da realidade em busca da dignidade. Porto Alegre: Livraria do Advogado Editora, 2010.

FOLHA DE SÃO PAUlO. Casais de Três ou Mais Parceiros Obtêm União com Papel Passado no Brasil. 2016. Disponível em: http://www1.folha.uol.com.br/cotidiano/2016/01/1732932-casais-de-3-ou-mais-parceirosobtem-uniao-com-papel-passado-no-brasil.shtml. Acesso em: 8 de dezembro de 2016

GAGLIANO, Pablo Stolze. PAMPLONA FILHO, Rodolfo. Direito das Sucessões. 3 ed. São Paulo: Saraiva, 2016.

GOMES, Orlando. Direito de Família. Rio de Janeiro: Forense, 2006.

GONÇALVES, Carlos Roberto. Direito Civil Brasileiro. Vol.7. $6^{\circ}$ ed. São Paulo: Saraiva. 2012.

HIRONAKA, Giselda Maria Fernandes Novaes. Direito das Sucessões Inventário e Partilha. Ed. 2. Belo Horizonte: Del Rey. 2007.

INSTITUTO BRASILEIRO DE DIREITO DE FAMILIA. Escritura Reconhece União Afetiva a Três. 2012. Disponível em: < http://www.ibdfam.org.br/noticias/4862/novosite>. Acesso em: 07 de dezembro de 2016.

LÔBO, Paulo. Famílias. 4. ed. São Paulo: Saraiva, 2012

MELO, Giovana Pelagio. Uniões Concomitantes. Trabalho de Conclusão de Curso apresentado pela Faculdade de Direito da Pontifícia Universidade Católica do Rio Grande do Sul 2010.2 Disponível em: 


\section{A CONSTITUCIONALIDADE DO POLIAMOR: POSSÍVEL APLICABILIDADE DO DIREITO SUCESSÓRIO AOS COMPANHEIROS DAS ENTIDADES POLIAFETIVAS}

http://www3.pucrs.br/pucrs/files/uni/poa/direito/graduacao/tcc/tcc2/trabalhos2010_2/giovana _melo.pdf $>$. Acesso em: 02 de abril de 2017.

MENIN, Márcia Maria. Da Sucessão Legítima. 2014. Disponível em: < http://www.direitorp.usp.br/wp-content/uploads/2014/11/artigo_marcia_maria_menin.pdf>. Acesso em: 10 de maio de 2017.

PEREIRA, Rodrigo da Cunha. Direito de Família: uma abordagem psicanalítica. $4^{\circ}$ ed. Belo Horizonte: Del Rey. 2012.

PILÃO, Antônio Cerdeira; GOLDENBERG, Mirian. Poliamor e Monogamia: Construindo Diferenças e Hierarquias. Revista Ártemis. Vol. 13. 2012. Disponível em: < http://periodicos.ufpb.br/ojs/index.php/artemis/article/viewFile/14231/8159>. Acesso em: 05 de janeiro de 2017.

RAMAlho NETO, Deodato José. A Possibilidade Do Poliamorismo Enquanto Direito Personalíssimo E A Ausência De Regulamentação No Direito Brasileiro. Artigo publicado pelo Conselho Nacional de Pesquisas e Pós-Graduação em Direito. 2015.

RODRIGUES, Liz Helena Silveira do Amaral. Amor Plural: Características, Diferenciações E Possibilidade De Reconhecimento De Relações Afetivo-Familiares Fundadas No Poliamor. $2015 . \quad$ Disponível em: http://www.publicadireito.com.br/artigos/?cod=2f4cd0a689df7a66. Acesso em: 17 de janeiro de 2017.

SANTIAGO, Rafael da Silva. O Mito da Monogamia à Luz do Direito CivilConstitucional: necessidade de uma proteção normativa às relações de poliamor. Dissertação apresentada ao Programa de Pós-Graduação em Direito da Universidade de Brasília (UNB). $2014 . \quad$ Disponível em: < http://repositorio.unb.br/bitstream/10482/16193/1/2014_RafaeldaSilvaSantiago.pdf $>$. Acesso em: 15 de dezembro de 2016.

SARLET, Wolfgang Ingo. Dignidade da pessoa humana e direitos fundamentais na Constituição da República de 1988. Porto Alegre: Livraria do Advogado, 2002. Disponível em: < https://www.maxwell.vrac.puc-rio.br/13488/13488_3.PDF>. Acesso em: 11 de maio de 2017.

SARLET, Ingo Wolfgang. A Eficácia dos Direitos Fundamentais. 5.ed. Revista, atualizada e ampliada. 5. ed. Porto Alegre: Livraria do Advogado, 2005. v. 1

SIMÃO, José Fernando. Há Limites Para O Princípio Da Pluralidade Familiar Na Apreensão De Novas Formas De Conjugalidade E De Parentesco? Revista Brasileira de Direito Civil. Vol. 2014. 2. Disponível em: < https://www.ibdcivil.org.br/image/data/revista/pdf/05---rbdcivil-volume-2---hua-limites-parao-princuapio-da-pluralidade-familiar-na-apreensueo-de-novas-formas-de-conjugalidade-e-deparentesco.pdf $>$. Acesso em: 06 de março de 2017. 
SIMÕES, Thiago Felipe Vargas. A Família Afetiva- O Afeto como Formador de Família. Revista $\quad$ Pensar. 2008. Disponível em: http://www3.promovebh.com.br/revistapensar/art/a19.pdf>. Acesso em: 15 de dezembro de 2017.

TANAKA, Auro Hadano; LINO, Leandro Jorge de Oliveira. Estudos De Julgados Sobre A Divisão Da Pensão Previdenciária

Por Morte Nas Famílias Simultâneas. Universidade Federal de São Paulo (UNIFESP). 2017.

TARTUCE, Flávio. Direito Civil. Vol.5. 12ª Ed. Rio de Janeiro: Forense. 2017.

TEIXEIRA, Daniele Chaves. Notas Sobre Planejamento Sucessório. Artigo publicado pelo Conselho Nacional de Pesquisa e Pós-Graduação em Direito (CONPEDI), 2015. Disponível em: $<$ http://www.conpedi.org.br/publicacoes/c178h0tg/aynm5hh3/025XE1rKIR1I3Dd4.pdf>. Acesso em: 24 de fevereiro de 2017. 